\title{
Thin Film Characteristics of Sn-3.5Ag-(2.0Cu) Alloy
}

\author{
Fei-Yi Hung*, Puo-Sheng Chen, Truan-Sheng Lui and Li-Hui Chen \\ Department of Materials Science and Engineering, National Cheng Kung University, Tainan, Taiwan, R. O. China
}

$\mathrm{Sn}-\mathrm{Ag}-\mathrm{Cu}$ lead-free solders have recently been applied generally in electrical packaging, but a discoloring of the solders often occurs at the injection-ball or the reflow processes. This study investigates the solidification surface characteristics of both the Sn-3.5Ag alloy and the Sn$3.5 \mathrm{Ag}-2.0 \mathrm{Cu}$ alloy to discuss and clarify the differences in composition between the surface and the thin film of subsurface. The results indicate that the solidification surface films of the $\mathrm{Sn}-3.5 \mathrm{Ag}-(2.0 \mathrm{Cu})$ are mostly composed of $\mathrm{SnO}$ phase and $\mathrm{SnO}_{2}$ phase. The concentration of $\mathrm{Sn}^{4+}$ is higher than that of $\mathrm{Sn}^{2+}$ on the film. And the binding energy of $\mathrm{O}$ atoms increases at sites near the solidification surface. On the solidification surface thin film, the $\mathrm{Ag}$ content of the $\mathrm{Sn}-3.5 \mathrm{Ag}-2.0 \mathrm{Cu}$ specimen is higher than the $\mathrm{Sn}-3.5 \mathrm{Ag}$ specimen. In addition, there is few $\mathrm{Cu}$ on the solidification surface film of the $\mathrm{Sn}-3.5 \mathrm{Ag}-2.0 \mathrm{Cu}$ specimen, and adding $\mathrm{Cu}$ into $\mathrm{Sn}-3.5 \mathrm{Ag}$ alloy not only can repress the growth of the $\mathrm{SnO}{ }_{x}$ phase but also reducing the degree of discoloring.

(Received April 18, 2005; Accepted October 20, 2005; Published December 15, 2005)

Keywords: lead-free solders, tin-silver-copper, oxide thin film, X-ray photoelectron spectroscopy (XPS), X-ray diffraction analysis (XRD)

\section{Introduction}

$\mathrm{Sn}-\mathrm{Ag}-\mathrm{Cu}$ alloy systems have been recognized as one of the best choices as a lead-free solder to replace conventional $\mathrm{Sn}-\mathrm{Pb}$ eutectic. ${ }^{1-3)}$ Following the size decrease of electrical packaging elements, the dimensions of the solders have also decreased. This has also led to a gradual increase in the importance of the solidification surface characteristics of tin balls. ${ }^{4,5)}$ As of now, the discoloring phenomenon often occurs at the tin ball surface under solidification processes, and a surface film with high roughness has also been observed at the solders. These effects are closely related to the quality of the solder and the solder joint reliability. ${ }^{6-8)}$ However, the characteristics of the solidification surface film have still not been examined. In order to understand the possible reasons for the color change effect, the current study will discuss the structure of the surface thin film. This study uses the Sn3.5Ag alloy and the $\mathrm{Sn}-3.5 \mathrm{Ag}-2.0 \mathrm{Cu}$ alloy to investigate the structural characteristics of the surface thin film under solidification, and a comparison is performed of the composition between the surface and the subsurface.

\section{Experimental Procedure}

Master alloys of the $\mathrm{Sn}-3.5 \mathrm{Ag}$ alloy and the $\mathrm{Sn}-3.5 \mathrm{Ag}-$ $2.0 \mathrm{Cu}$ alloy were prepared by melting pure tin, pure silver and pure copper in a high-frequency induction furnace. The alloy ingots were then remelted and cast into a Y-shaped graphite mold. For the casting process, the tin alloy melting temperature was selected to be $310^{\circ} \mathrm{C}$ and the temperature for the graphite mold was $230^{\circ} \mathrm{C}$, followed by cooling to room temperature. In order to collect the solidification film data, rectangular specimens (gauge length section: $10 \mathrm{~mm} \times$ $10 \mathrm{~mm} \times 2 \mathrm{~mm}$ ) were also prepared to perform thin-film XRD and XPS analysis.

For surface analysis, the solidification surface of the specimens with no treatment will hereafter be referred to as "surface" (the surface of the specimens possessed a light yellow color). After polishing the solidification surface of the

*Corresponding author, E-mail: fyhung@mail.mse.ncku.edu.tw specimens, a silver color was obtained and this will be referred to as "subsurface". The microstructures of the alloys were determined using an image analyzer. In addition, both XPS and thin-film XRD were also used to obtain data of the surface and the subsurface. For thin-film XRD analysis, the $\mathrm{Cu}-\mathrm{K} \alpha$ standard $(\lambda=1.5403 \mathrm{~nm})$ was selected for $\mathrm{X}$-ray diffraction. The scanning angle was varied from $20^{\circ}$ to $90^{\circ}$ and the scanning velocity was $3^{\circ} \cdot \mathrm{min}^{-1}$. In order to compare the experimental results, the solidification film data of the pure tin specimen was also examined using the thin-film XRD analysis method.

\section{Results and Discussion}

Figure 1 shows the microstructures of the $\mathrm{Sn}-3.5 \mathrm{Ag}$ and the $\mathrm{Sn}-3.5 \mathrm{Ag}-2.0 \mathrm{Cu}$ alloy. A previous study of $\mathrm{Sn}-3.5 \mathrm{Ag}-$ $\mathrm{xCu}(\mathrm{x}=0-2.0$ mass $\%)$ alloys revealed that the $\mathrm{Cu}_{6} \mathrm{Sn}_{5}$ compounds increased and the shape of $\beta$-Sn phase transformed from dendrite into dispersed with increasing the $\mathrm{Cu}$ content. In addition, dendritic $\beta$-Sn phase and eutectic phase were also observed in the $\mathrm{Sn}-3.5 \mathrm{Ag}$ alloy [see Fig. 1(a)]. In Fig. 1(b), precipitated $\mathrm{Cu}_{6} \mathrm{Sn}_{5}$ was produced in $\beta$-Sn phase. $\mathrm{Ag}_{3} \mathrm{Sn}$ phase was not observed in either Figs. 1(a) or (b). In order to examine the difference in composition between the surface and the subsurface, thin-film XRD analysis of the $\mathrm{Sn}-$ $3.5 \mathrm{Ag}$ and the $\mathrm{Sn}-3.5 \mathrm{Ag}-2.0 \mathrm{Cu}$ alloy were performed.

Figure 2 shows the thin-film X-ray diffractive patterns of the $\mathrm{Sn}-3.5 \mathrm{Ag}$ alloy. The evidence reveals that both $\beta$-Sn phase and $\mathrm{Ag}_{3} \mathrm{Sn}$ phase existed at the surface and the subsurface. As for the relative composition, the content of $\mathrm{Ag}_{3} \mathrm{Sn}$ phase had increased only very slightly from the surface to subsurface. To compare the data, thin-film XRD analysis of the $\mathrm{Sn}-3.5 \mathrm{Ag}-2 \mathrm{Cu}$ alloy was also performed (see Fig. 3). In addition to $\beta$-Sn phase, $\mathrm{Ag}_{3} \mathrm{Sn}$ compounds and $\mathrm{Cu}_{6} \mathrm{Sn}_{5}$ compounds also formed, and the content of the latter two compounds also had a tendency to increase from the surface to the subsurface. The secondary ion mass spectrometry (SIMS) data of the $\mathrm{Sn}-3.5 \mathrm{Ag}-2 \mathrm{Cu}$ alloy also revealed that both the concentration of ${ }^{63} \mathrm{Cu}^{-}$and ${ }^{107} \mathrm{Ag}^{-}$were lower near the surface in relative composition (not given here). The solidification surface films of both the $\mathrm{Sn}-3.5 \mathrm{Ag}$ specimen 


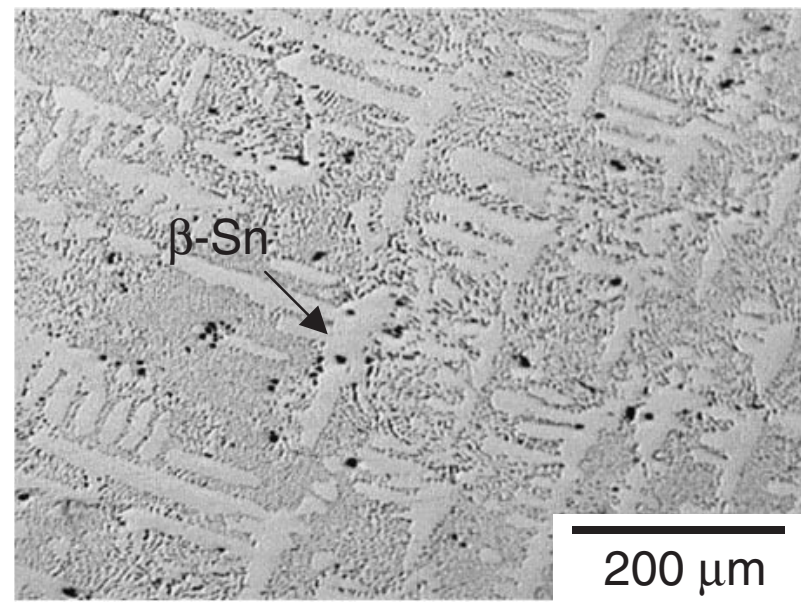

(a)

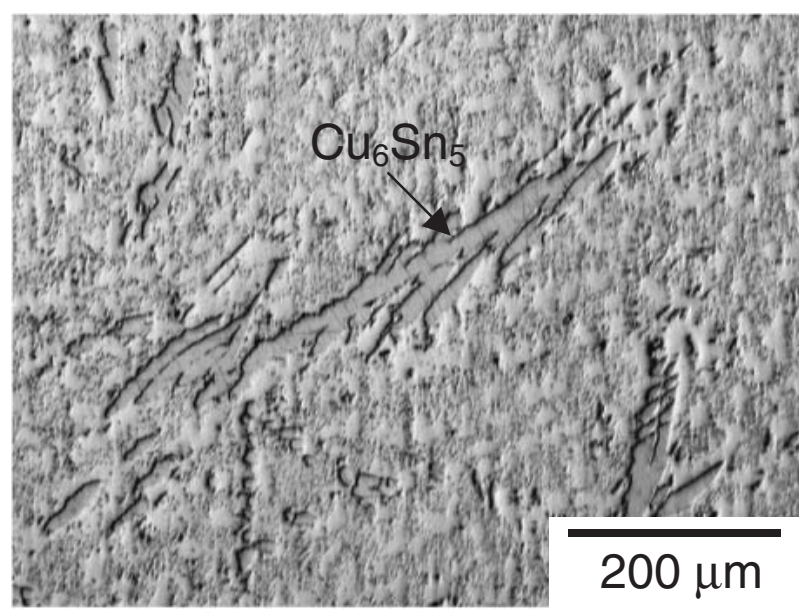

(b)

Fig. 1 Microstructure of the alloy: (a) $\mathrm{Sn}-3.5 \mathrm{Ag}$, (b) $\mathrm{Sn}-3.5 \mathrm{Ag}-2 \mathrm{Cu}$.

and $\mathrm{Sn}-3.5 \mathrm{Ag}-2.0 \mathrm{Cu}$ specimen exhibited discoloring, but neither Figs. 2 nor 3 can explain the mechanism of the solidification surface film completely. In order to understand the solidification thin film characteristics, XPS was performed at the surface and the subsurface.

Figure 4 shows the full XPS spectra of both the $\mathrm{Sn}-3.5 \mathrm{Ag}$ specimen and the $\mathrm{Sn}-3.5 \mathrm{Ag}-2.0 \mathrm{Cu}$ specimen. Figure 4 reveals differences between the surface and the subsurface. In Fig. 4(a), comparing the surface with the subsurface, a large amount of $\mathrm{Sn}\left(\mathrm{Sn} 3 \mathrm{~s}^{1}\right)$ or $\mathrm{SnO}_{x}\left(\mathrm{Sn} 3 \mathrm{p}^{3}\right)$ was found at the subsurface. For the $\mathrm{Sn}-3.5 \mathrm{Ag}-2.0 \mathrm{Cu}$ alloy [see Fig. 4(b)], the subsurface also contained a larger amount of $\mathrm{Sn}\left(\mathrm{Sn} 3 \mathrm{~s}^{1}\right)$ or $\mathrm{SnO}_{x}\left(\mathrm{Sn}_{3} \mathrm{p}^{3}\right)$ than the surface. According to the above findings, the full XPS spectra was unable to differentiate between $\mathrm{Sn}$ and $\mathrm{SnO}_{x}$ phase. Moreover, the concentration of every element in the experimental specimen was also analyzed by XPS to explain the thin film characteristics.

A comparison of the XPS-Sn analysis on the $\mathrm{Sn}-3.5 \mathrm{Ag}$ alloy and the $\mathrm{Sn}-3.5 \mathrm{Ag}-2.0 \mathrm{Cu}$ alloy is shown in Fig. 5. The surface peaks of both specimens are of the single-peak type, and their subsurface peaks are of the double-peak type. Thus it can be seen that there is an obvious difference between the chemical combination of $\mathrm{Sn}$ at the surface and the subsurface.

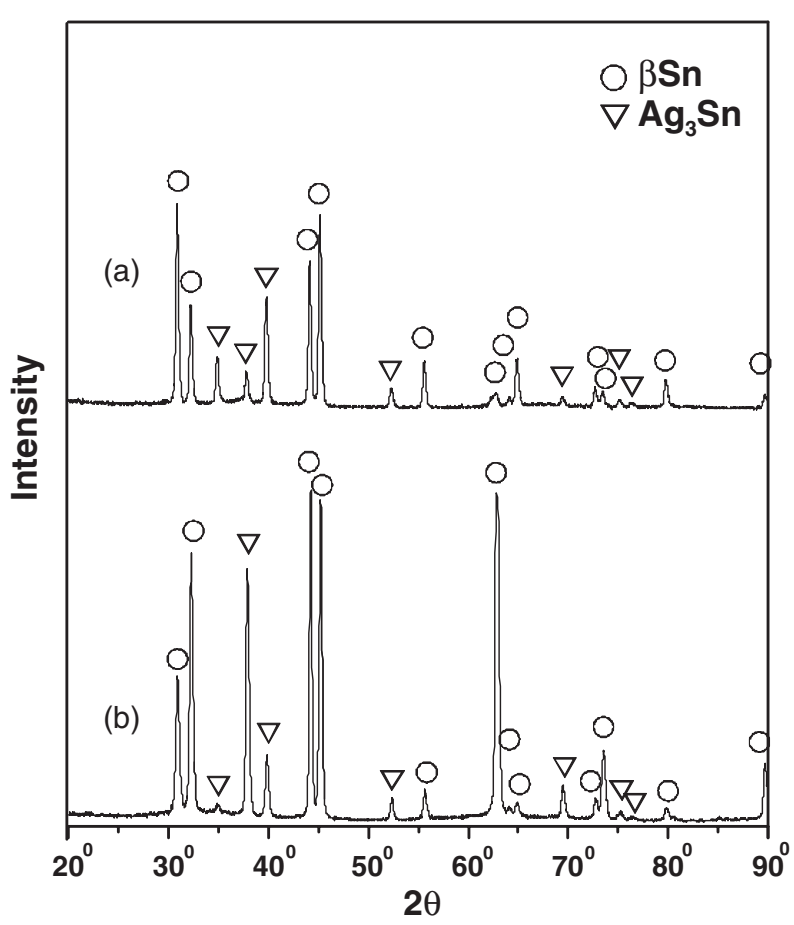

Fig. 2 Thin-film XRD patterns of the $\mathrm{Sn}-3.5 \mathrm{Ag}$ specimen: (a) surface, (b) subsurface.

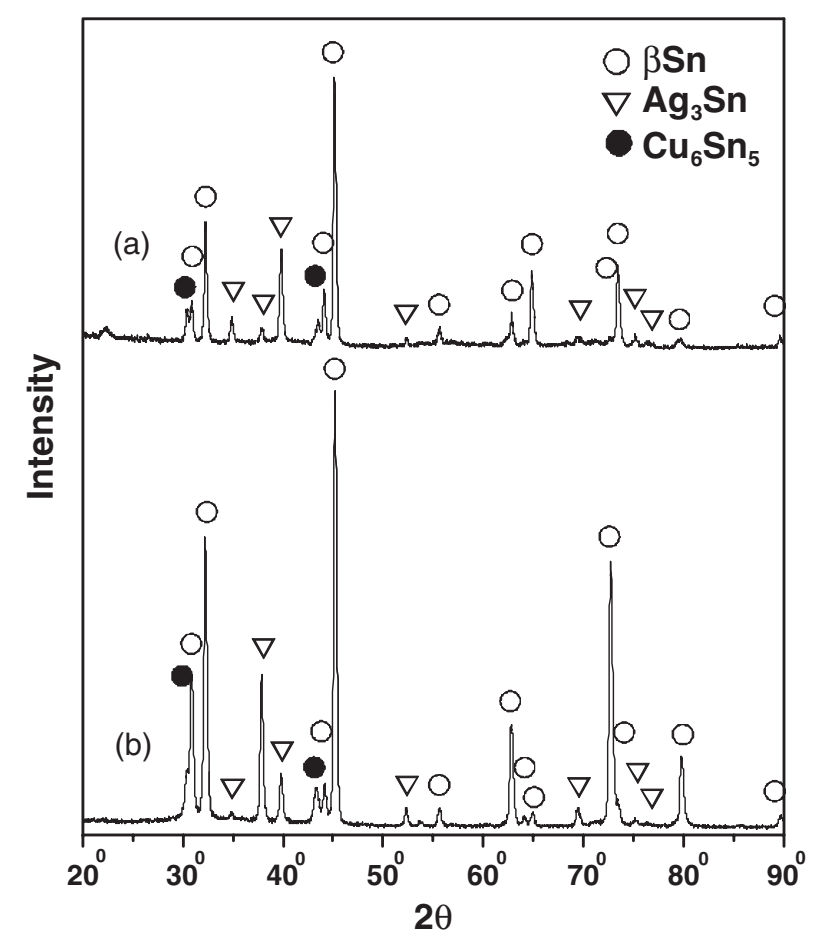

Fig. 3 Thin-film XRD patterns of the $\mathrm{Sn}-3.5 \mathrm{Ag}-2 \mathrm{Cu}$ specimen: (a) surface, (b) subsurface.

XPS-Ag analysis on both the Sn-3.5Ag alloy and the Sn$3.5 \mathrm{Ag}-2.0 \mathrm{Cu}$ alloy (see Fig. 6) revealed that the Ag content at the surface was very low and the majority of Ag was found at the subsurface. Comparing the Ag content on the surface of the two specimens, the Ag content had a very slight tendency to increase as $\mathrm{Cu}$ was added. XPS- $\mathrm{Cu}$ analysis of the $\mathrm{Sn}-$ $3.5 \mathrm{Ag}-2.0 \mathrm{Cu}$ specimen shows that there was no detectable 


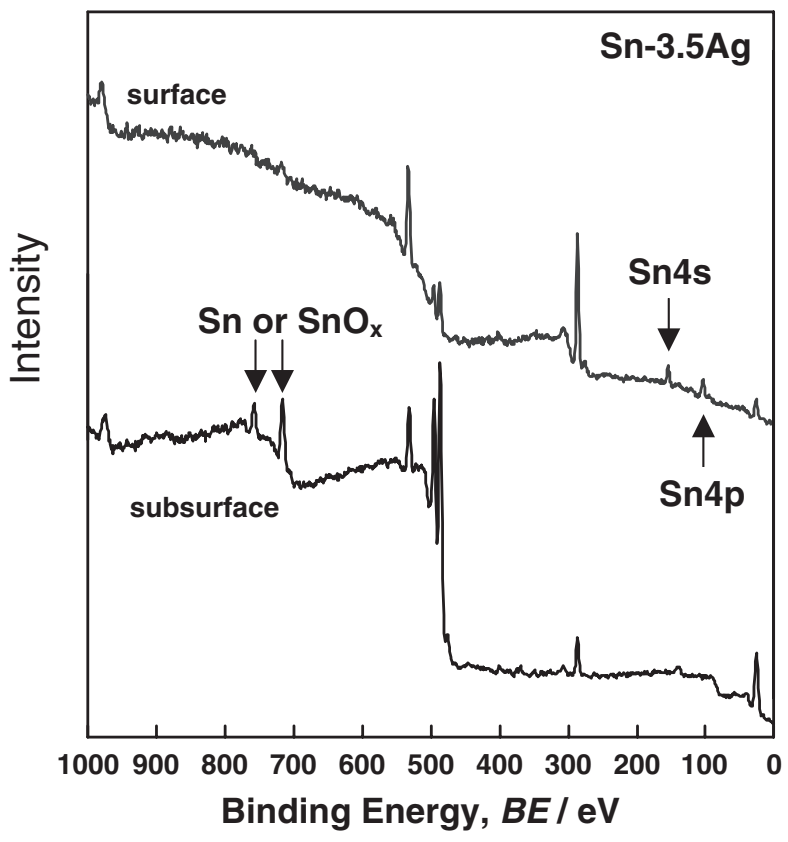

(a)

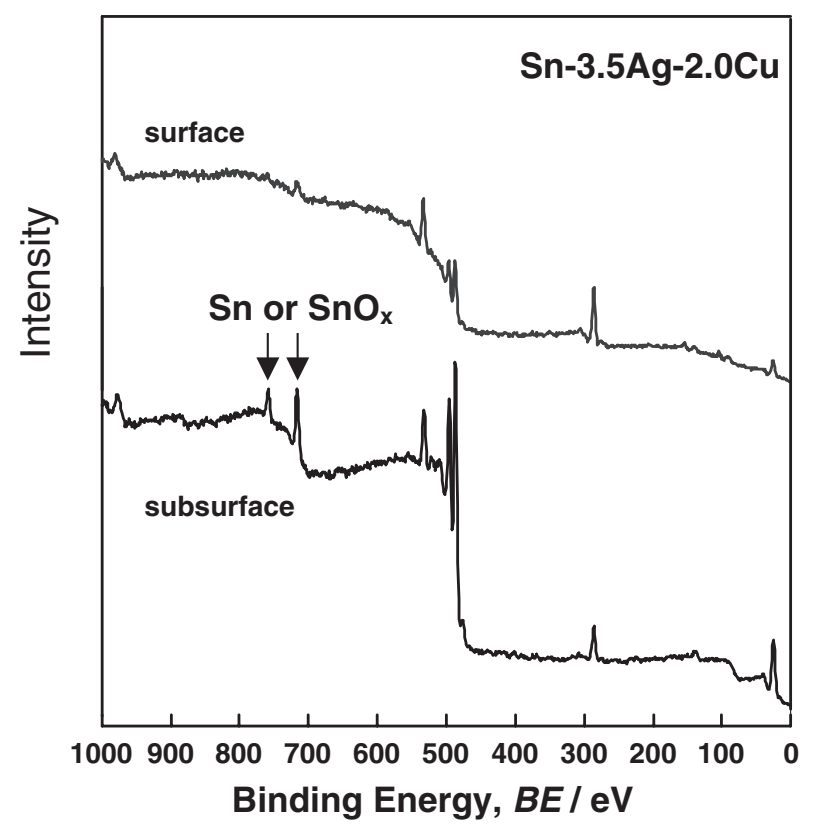

(b)

Fig. 4 Full-XPS spectra: (a) Sn-3.5Ag, (b) Sn-3.5Ag-2.0Cu.

$\mathrm{Cu}$ at the surface. Figure 7 shows a comparison of the XPS$\mathrm{O}$ analysis on the $\mathrm{Sn}-3.5 \mathrm{Ag}$ alloy and the $\mathrm{Sn}-3.5 \mathrm{Ag}-2.0 \mathrm{Cu}$ alloy. It can be seen that the binding energy of $\mathrm{O}$ increased from the subsurface to the surface.

The curve-fitting data of XPS-Sn analysis on the Sn$3.5 \mathrm{Ag}$ alloy and the $\mathrm{Sn}-3.5 \mathrm{Ag}-2.0 \mathrm{Cu}$ alloy are shown in Figs. 8 and $9^{9,10)}$ (based on the single-peak spectrum curve and double-peak spectrum curve of Fig. 5). In Fig. 8 ( $\mathrm{Sn}-$ $3.5 \mathrm{Ag}$ specimen), the single-peak curves of the surface and the double-peak curves of the subsurface are composed of three curves, namely $\mathrm{Sn}^{0}, \mathrm{Sn}^{2+}$ and $\mathrm{Sn}^{4+}$ curves. As for relative composition, the $\mathrm{Sn}^{0}$ content of the subsurface was higher than the surface, and both the $\mathrm{Sn}^{2+}$ and $\mathrm{Sn}^{4+}$ content

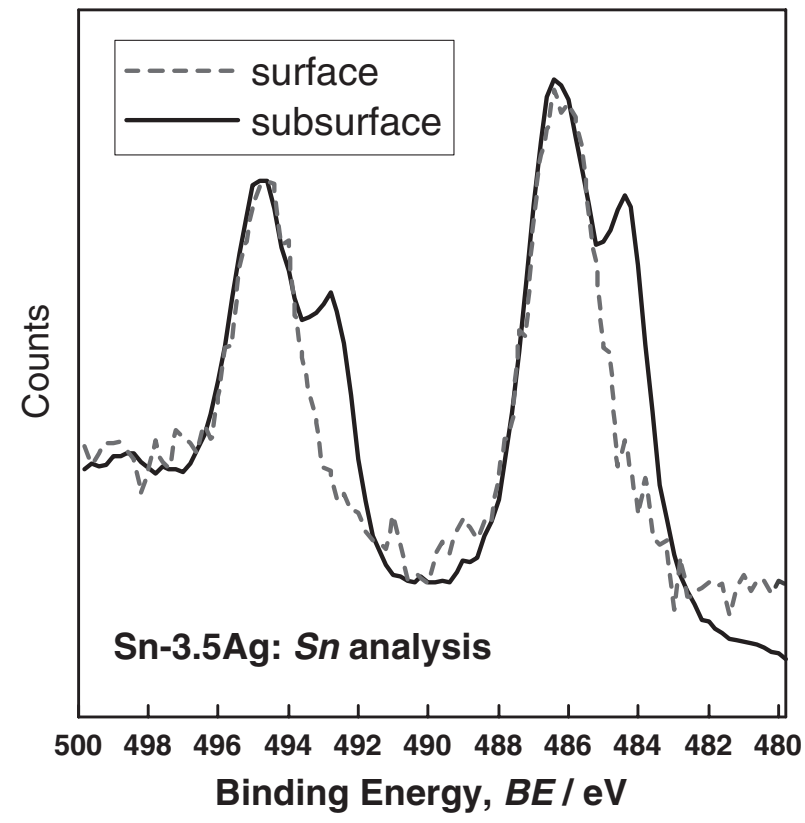

(a)

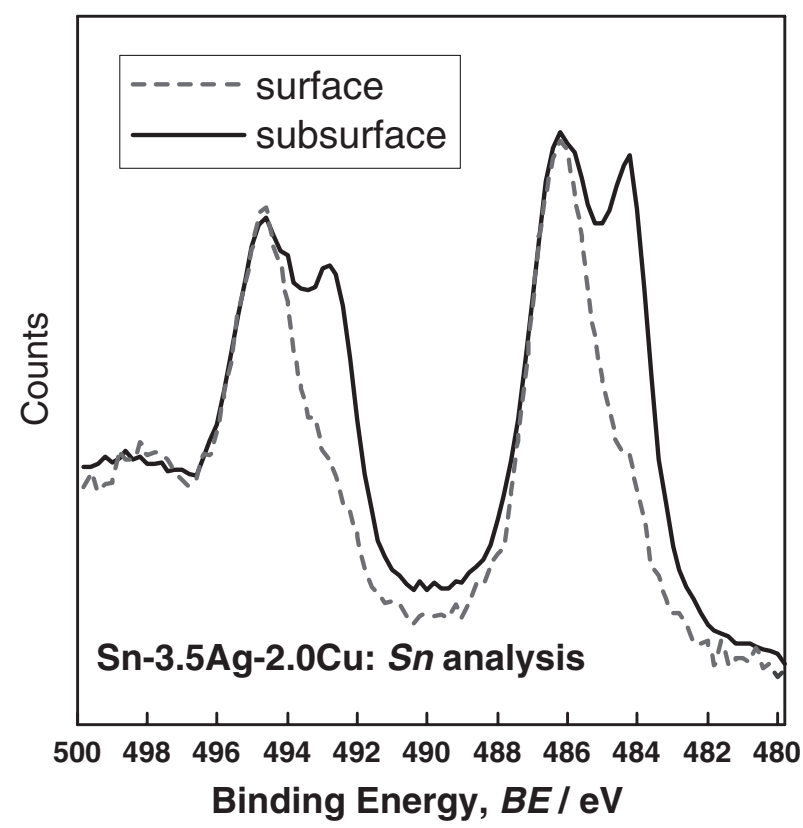

(b)

Fig. 5 XPS-Sn analysis: (a) Sn-3.5Ag, (b) Sn-3.5Ag-2.0Cu.

were lower at the subsurface. So, the content of both the $\mathrm{Sn}^{2+}$ and $\mathrm{Sn}^{4+}$ were closely related to the discoloring.

A similar phenomenon also occurred in the $\mathrm{Sn}-3.5 \mathrm{Ag}-$ 2.0Cu specimen (see Fig. 9). Notably, the $\mathrm{Sn}^{2+}$ and $\mathrm{Sn}^{4+}$ spectra are still observed at the subsurface of Figs. 8 or 9 . The evidence shows that tin alloys are highly susceptible to oxidation in air. In addition, the peak of the $\mathrm{Sn}^{0}$ fitting-curve increased while the peak of the $\mathrm{Sn}^{2+}$ curve decreased from surface to subsurface, resulting in the spectrum curve of the real XPS-Sn transforming from double-peak type to the single-peak type. In other words, it can be inferred that oxidation occurred obviously at the surface. To understand the reaction mechanism of the $\mathrm{Sn}^{2+}, \mathrm{Sn}^{4+}$ and O, XPS-O 


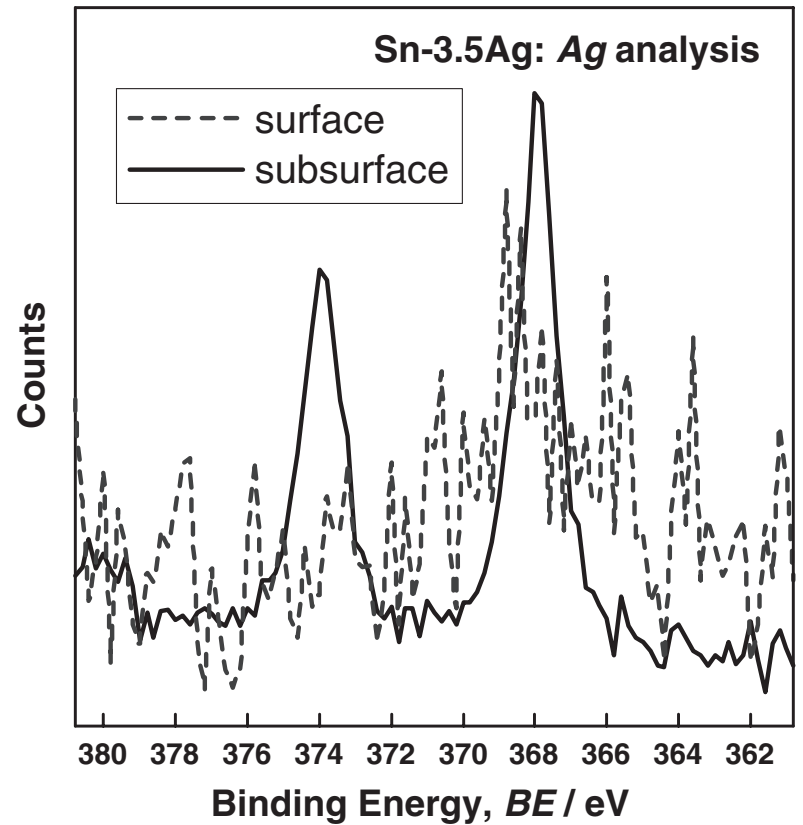

(a)

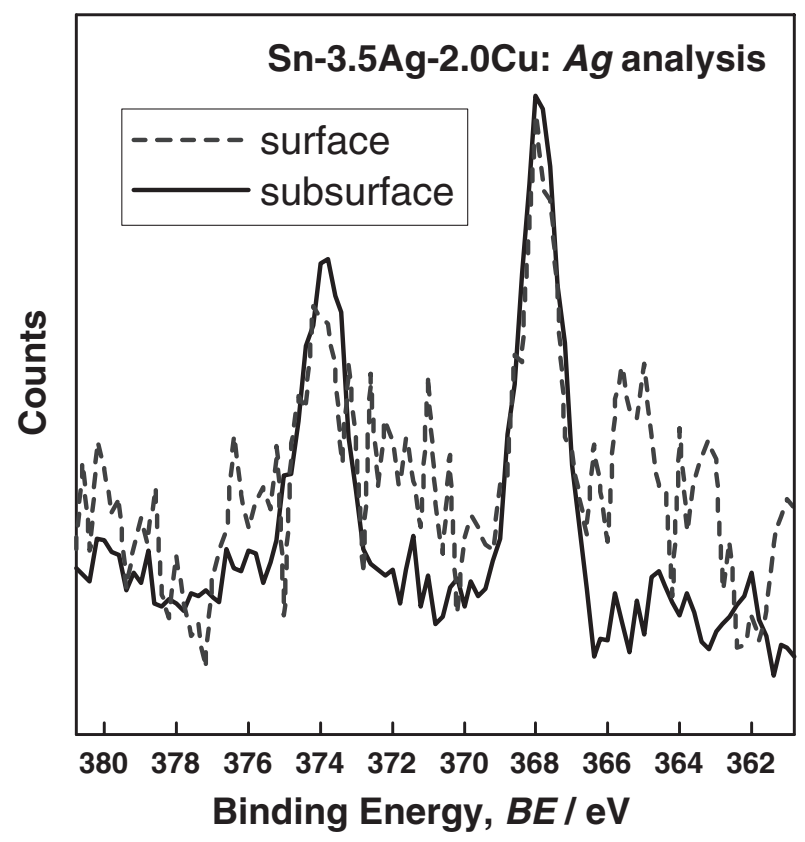

(b)

Fig. 6 XPS-Ag analysis: (a) $\mathrm{Sn}-3.5 \mathrm{Ag}$, (b) $\mathrm{Sn}-3.5 \mathrm{Ag}-2.0 \mathrm{Cu}$.

analysis of the curve fitting of the $\mathrm{Sn}-3.5 \mathrm{Ag}-2.0 \mathrm{Cu}$ was performed (see Fig. 10). Ignoring the atmosphere, the results indicate that the solidification surface thin film and the subsurface film were mostly composed of $\mathrm{SnO}$ phase and $\mathrm{SnO}_{2}$ phase. The roughness of the solidification surface film was greater than that of the subsurface, resulting in the atmosphere fitting-curve of Fig. 10(a) possessing higher intensity than Fig. 10(b). To sum up the data of Figs. 5 and $8-10$, the solidification surface oxidative films of both the $\mathrm{Sn}-3.5 \mathrm{Ag}$ specimen and the $\mathrm{Sn}-3.5 \mathrm{Ag}-2.0 \mathrm{Cu}$ specimen were mostly composed of $\mathrm{SnO}$ and $\mathrm{SnO}_{2}$. For the $\mathrm{Sn}-3.5 \mathrm{Ag}-2.0 \mathrm{Cu}$ specimen, a little $\mathrm{Ag}$ was able to exist (possibly as $\mathrm{Ag}_{3} \mathrm{Sn}$ compounds) at the solidification surface oxidative films.

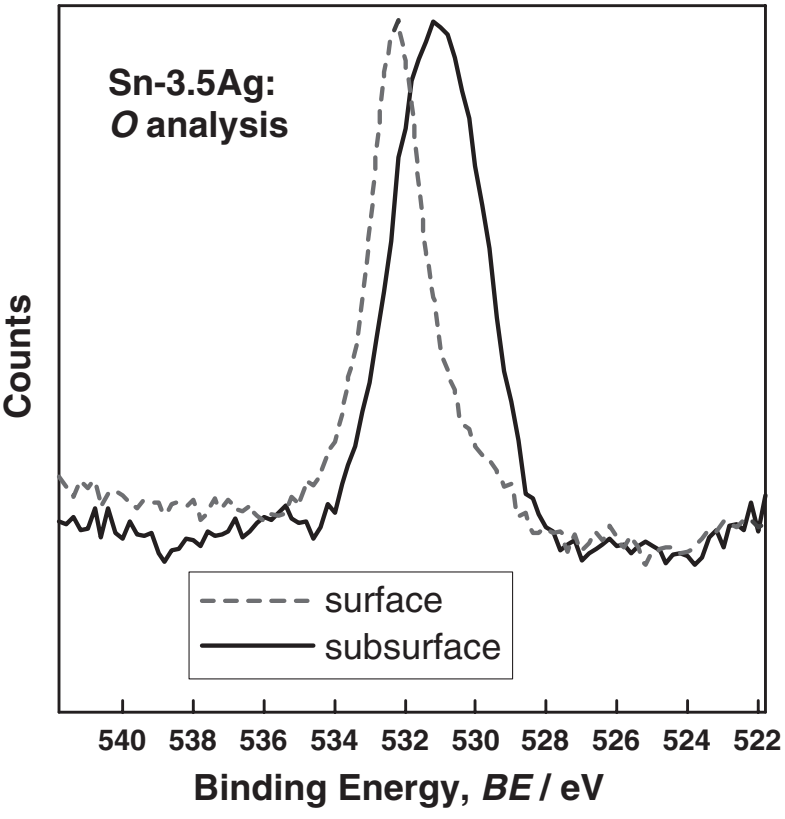

(a)

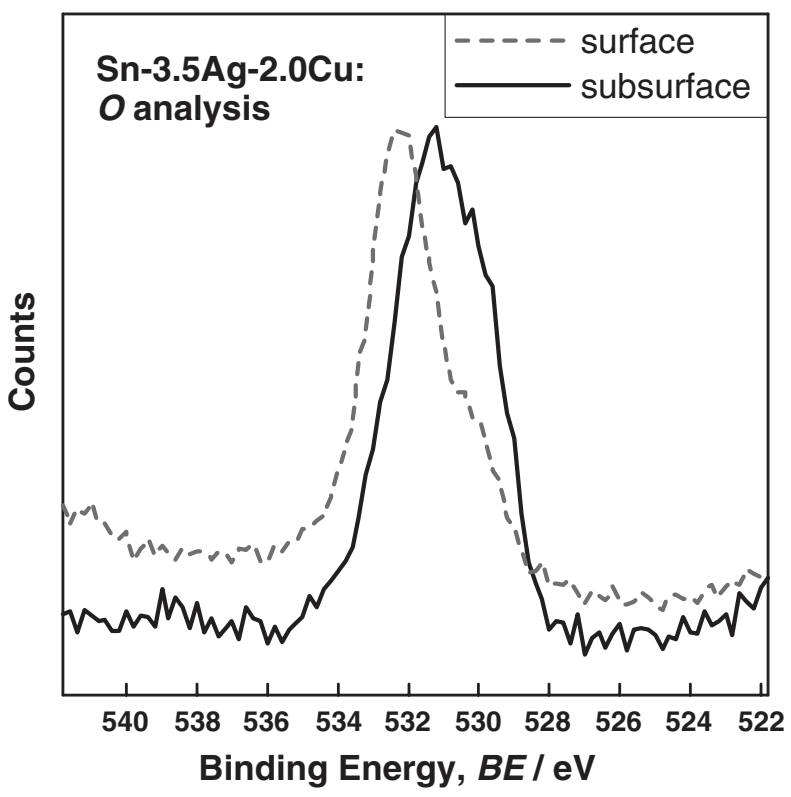

(b)

Fig. 7 XPS-O analysis: (a) $\mathrm{Sn}-3.5 \mathrm{Ag}$, (b) $\mathrm{Sn}-3.5 \mathrm{Ag}-2.0 \mathrm{Cu}$.

Meanwhile, the intensity of the Sn fitting curve of Figs. 8(a) and 9(a) also explains how $\mathrm{Cu}$ repressed the growth of $\mathrm{SnO}_{x}$ in the $\mathrm{Sn}-3.5 \mathrm{Ag}$ alloy. So, the possible copper-microsegregation is not the main reason for the discoloring phenomenon. The $\mathrm{SnO}$ and $\mathrm{SnO}_{2}$ of the solidification surface affected the degree of discoloring.

The thin-film XRD results of both Figs. 2 and 3 cannot provide a complete profile of the solidification oxidative films. Therefore, this study avoided the influence of Ag and $\mathrm{Cu}$, selecting a pure $\mathrm{Sn}$ specimen to perform thin-film XRD analysis (see Fig. 11, the conditions are the same as Figs. 2 and 3). Both $\mathrm{SnO}$ phase and $\mathrm{SnO}_{2}$ phase were found on the solidification surface oxidative film. So it is safe to say that the $\mathrm{Ag}_{3} \mathrm{Sn}$ compounds affected the thin-film XRD analysis of 


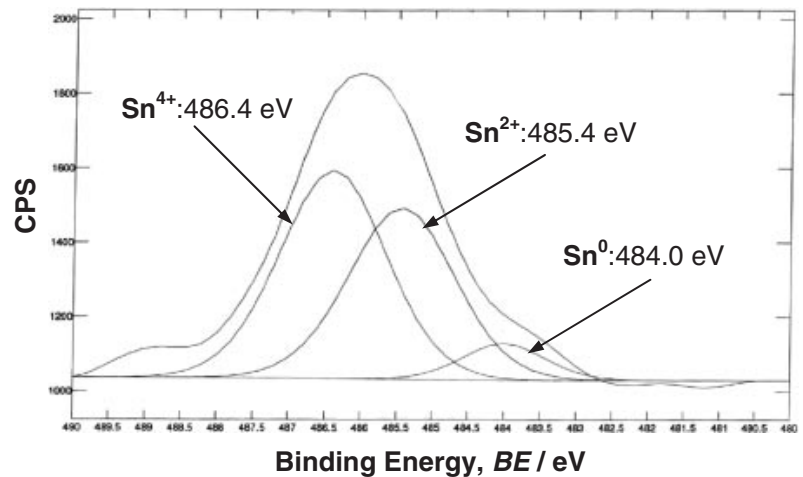

(a)

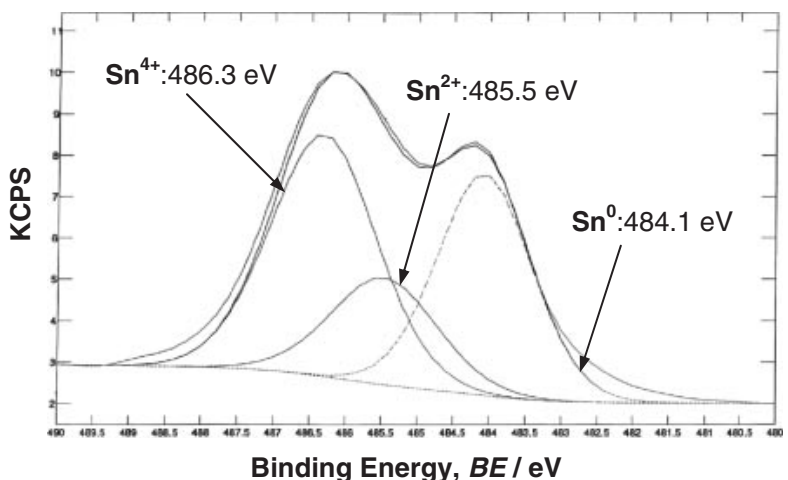

(b)

Fig. 8 Sn-3.5Ag/XPS-Sn analysis: (a) surface, (b) subsurface.

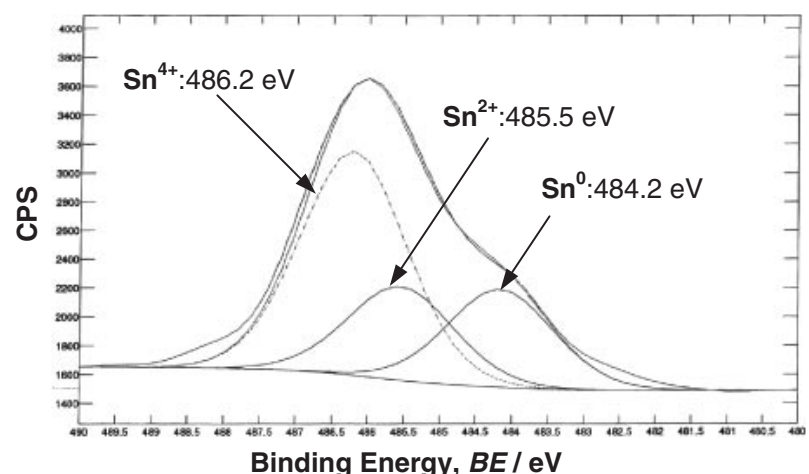

(a)

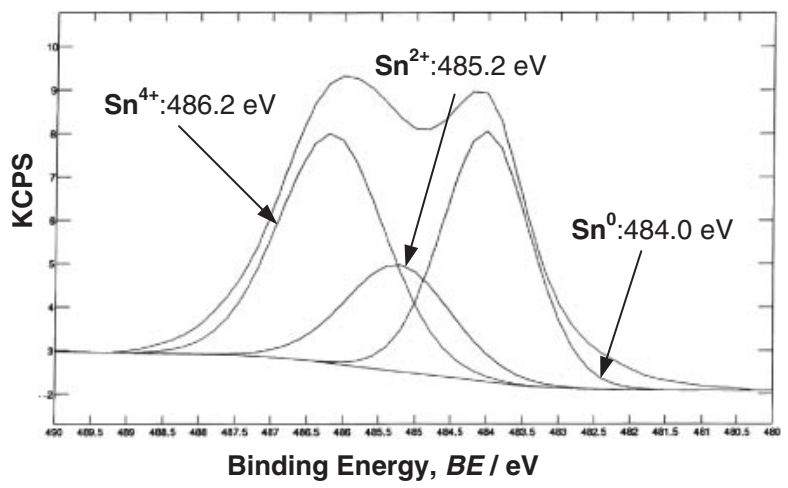

(b)

Fig. 9 Sn-3.5Ag-2Cu/XPS-Sn analysis: (a) surface, (b) subsurface.

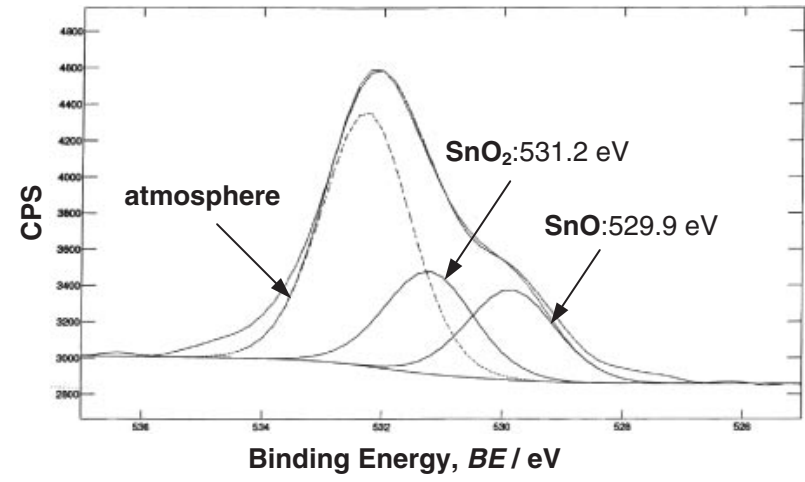

(a)

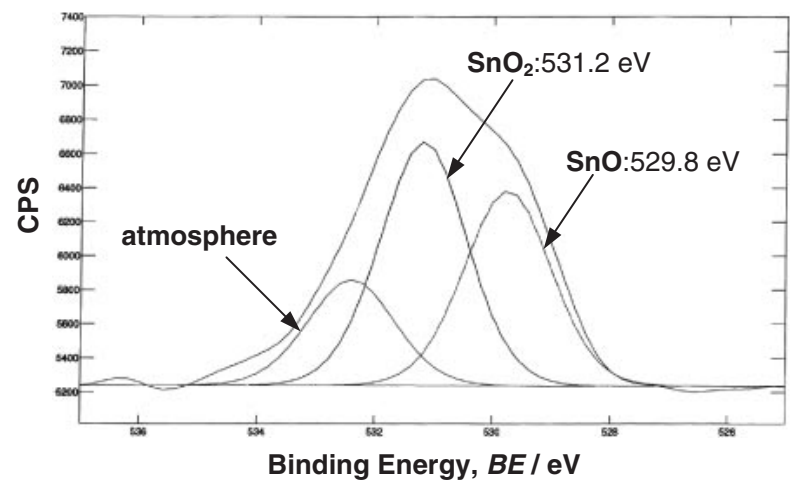

(b)

Fig. $10 \mathrm{Sn}-3.5 \mathrm{Ag}-2 \mathrm{Cu} / \mathrm{XPS}-\mathrm{O}$ analysis: (a) surface, (b) subsurface

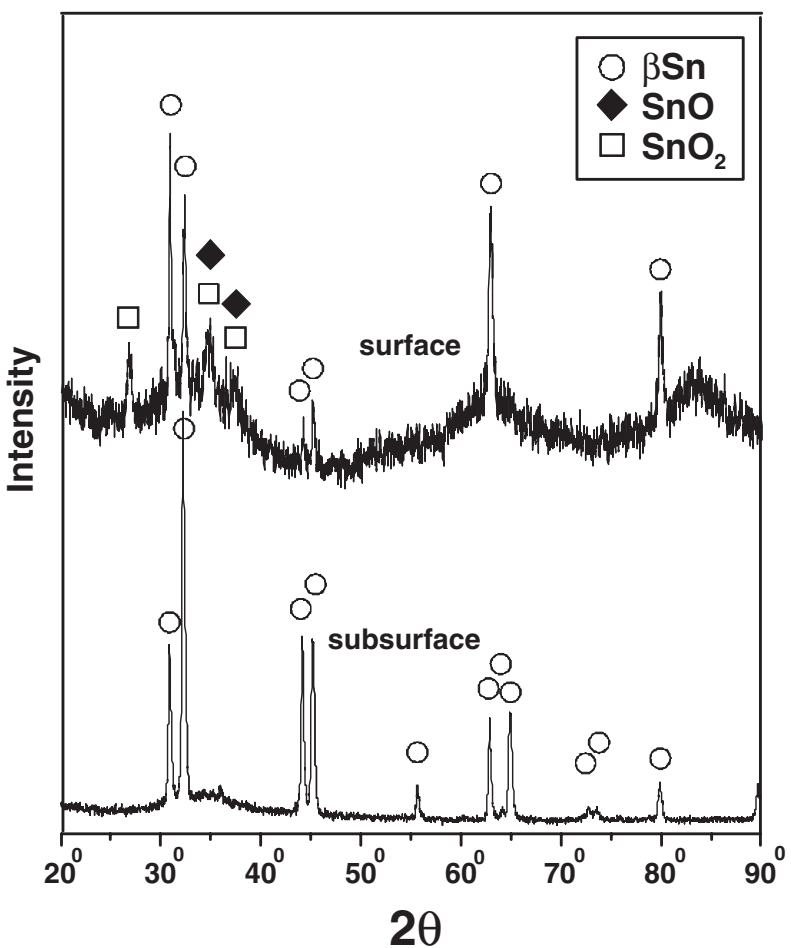

Fig. 11 Thin-film XRD analysis of the pure Sn specimen. 
the surface oxidative film in this system (the diffractive peak of both the $\mathrm{Ag}_{3} \mathrm{Sn}$ phase and the $\mathrm{SnO}$ phase are confused easily, $2 \theta=30^{\circ}-40^{\circ}$ ). For this reason, the analytic methods of the surface oxidative film of tin alloys must be chosen very carefully. Additionally, according to the Gibbs free energy ${ }^{11)}$ of $\mathrm{Sn}, \mathrm{Ag}, \mathrm{Cu}$ and $\mathrm{O}$, most of the $\mathrm{O}$ atoms and the $\mathrm{Sn}$ atoms in both the $\mathrm{Sn}-3.5 \mathrm{Ag}$ alloy and the $\mathrm{Sn}-3.5 \mathrm{Ag}-2.0 \mathrm{Cu}$ alloy react to form the oxidative film of $\mathrm{SnO}_{x}$. This explains how the $\mathrm{O}$ reacted with $\mathrm{Sn}$ melt to produce the oxidative film of $\mathrm{SnO}_{x}$ during the solidification process. Meanwhile, no AgO phase or $\mathrm{Cu}_{x} \mathrm{O}$ phase was found at the solidification surface thin films.

\section{Conclusion}

(1) Adding 2.0 mass $\% \mathrm{Cu}$ into the $\mathrm{Sn}-3.5 \mathrm{Ag}$ alloy, precipitated $\mathrm{Cu}_{6} \mathrm{Sn}_{5}$ was produced in the $\beta$-Sn phase. The two kinds of solidification surface oxidative films of the $\mathrm{Sn}-$ $3.5 \mathrm{Ag}$ specimen and the $\mathrm{Sn}-3.5 \mathrm{Ag}-2.0 \mathrm{Cu}$ specimen were mostly composed of $\mathrm{SnO}$ and $\mathrm{SnO}_{2}$. $\mathrm{Cu}$ can repress the growth of $\mathrm{SnO}_{x}$ phase in the $\mathrm{Sn}-3.5 \mathrm{Ag}$ alloy. The $\mathrm{SnO}$ and $\mathrm{SnO}_{2}$ of the solidification surface affected the degree of discoloring.

(2) On the solidification surface films, the Ag content of the $\mathrm{Sn}-3.5 \mathrm{Ag}-2.0 \mathrm{Cu}$ specimen was higher than the $\mathrm{Sn}-$ $3.5 \mathrm{Ag}$ specimen. There was almost no $\mathrm{Cu}$ on the solidification surface of the $\mathrm{Sn}-3.5 \mathrm{Ag}-2.0 \mathrm{Cu}$ specimen. As for the $\mathrm{Sn}-3.5 \mathrm{Ag}-(2.0 \mathrm{Cu})$ films, the $\mathrm{Sn}^{4+}$ concentration was higher than that of the $\mathrm{Sn}^{2+}$. The binding energy of $\mathrm{O}$ increases when the site is near the solidification surface.

\section{Acknowledgements}

The authors are grateful to the Chinese National Science Council for its financial support (Contract: NSC 94-2216-E006-008).

\section{REFERENCES}

1) K. S. Kim, S. H. Huh and K. Suganuma: Mater. Sci. Eng. A 333 (2003) 106-114.

2) W. Yang, L. E. Felton and R. W. Messler: J. Electron. Mater. 24 (1995) 1465-1472.

3) J. M. Song, F. I. Li, T. S. Lui and L. H. Chen: J. Mater. Res. 19 (2004) 2665-2673.

4) K. Suganuma and K. Kim: J. High Temp. Soc. Jpn. 30 (2004) 185-190.

5) NEC CORPORATION; Solder Coat Co., Ltd. Patent no. EP1088615 (2001).

6) D. Q. Yu, J. Zhao and L. Wang: J. Alloys Comp. 366 (2004) 170-175.

7) B. Salam, C. Virseda, H. Da, N. N. Ekere and R. Durairaj: Soldering and Surf. Mount Technol. 16 (2004) 27-23.

8) P. Breuil, C. Pijolat and R. Lalauze: Silicates Industriels. 55 (1990) 9194.

9) D. N. Wang, A. C. Miller and M. R. Notis: Surf. Interface Anal. 24 (1996) 127-132.

10) B. Vincent Crist: Handbook of Monochromatic XPS Spectra, The Elements and Native Oxides, John Wiley \& Sons, Ltd. (2000) pp. 471475.

11) B. J. Clark: Principles of Extractive Metallurgy, (McGraw-Hill series in materials science and engineering, 1974) p. 516. 